\title{
Eosinophils subvert host resistance to an intracellular pathogen by instigating non-protective IL-4 in CCR2 ${ }^{-/}$mice
}

\author{
AH Verma ${ }^{1,2,5,6}$, CL Bueter ${ }^{2,6}$, ME Rothenberg ${ }^{3}$ and GS Deepe R.4 $^{2,4}$
}

Eosinophils contribute to type II immune responses in helminth infections and allergic diseases; however, their influence on intracellular pathogens is less clear. We previously reported that $\mathrm{CCR}^{-\prime}$ mice exposed to the intracellular fungal pathogen Histoplasma capsulatum exhibit dampened immunity caused by an early exaggerated interleukin (IL)- 4 response. We sought to identify the cellular source promulgating IL-4 in infected mutant animals. Eosinophils were the principal instigators of non-protective IL-4 and depleting this granulocyte population improved fungal clearance in $\mathrm{CCR}^{-1-}$ animals. The deleterious impact of eosinophilia on mycosis was also recapitulated in transgenic animals overexpressing eosinophils. Mechanistic examination of IL-4 induction revealed that phagocytosis of $H$. capsulatum via the pattern recognition receptor complement receptor (CR) 3 triggered the heightened IL-4 response in murine eosinophils. This phenomenon was conserved in human eosinophils; exposure of cells to the fungal pathogen elicited a robust IL-4 response. Thus, our findings elucidate a detrimental attribute of eosinophil biology in fungal infections that could potentially trigger a collapse in host defenses by instigating type II immunity.

\section{INTRODUCTION}

Type II immune responses represent an effective strategy developed by the host to combat helminth parasites. ${ }^{1}$ Several effector functions associated with anti-helminth immunity are mediated by interleukin (IL)- 4 and IL-13. ${ }^{2,3}$ IL- 4 exhibits a pathologic role in the scenario of intracellular infections $s^{4,5}$ and allergic diseases such as asthma and eczema. ${ }^{6,7} \mathrm{~A}$ long standing interest in the field has been to identify initial cellular sources of IL-4 that trigger type II immune responses. Leukocytes including eosinophils, mast cells, basophils, NKT cells, and the recently described group 2 innate lymphoid cells have been implicated as potential sources of innate IL-4 in vivo. ${ }^{8-12}$ Eosinophils, in particular, store preformed IL-4 within intracellular crystalloid granules that are rapidly secreted upon cell activation. ${ }^{13}$ This eosinophil-derived IL-4 contributes to the development of $\mathrm{T}_{\mathrm{H}} 2$ cells in allergic disorders $^{14}$ and regulates metabolic homeostasis through maintenance of alternatively activated macrophages in adipose tissues. $^{15}$

Histoplasma capsulatum is a prototypical intracellular pathogen that causes a wide spectrum of illness. The fungus is found globally but is endemic to midwestern and southeastern US and Central and South America. ${ }^{16}$ Although it produces a primary infection, it also acts as an opportunist in immunocompromised patients such as those suffering from AIDS. An estimated 25000 life threatening H. capsulatum infections are reported every year in the United States. ${ }^{17}$ In contrast, infections in immunocompetent individuals are generally asymptomatic and efficiently resolved.

Successful clearance of $H$. capsulatum is dependent on the coordinated action of innate and adaptive immune responses. In the environment, the pathogen gains entry into the host through the pulmonary route, wherein it is internalized by phagocytes. Ingestion of the organism via the pattern

\footnotetext{
'Division of Immunobiology, Cincinnati Children's Hospital Medical Center, University of Cincinnati, Cincinnati, Ohio, USA. ²Division of Infectious Diseases, University of Cincinnati College of Medicine, Cincinnati, Ohio, USA. ${ }^{3}$ Division of Allergy and Immunology, Cincinnati Children's Hospital Medical Center, University of Cincinnati, Cincinnati, Ohio, USA and ${ }^{4}$ Veterans Affairs Hospital, Cincinnati, Ohio, USA. Correspondence: GS Deepe (george.deepe@uc.edu)

${ }^{5}$ Present address: Division of Rheumatology and Clinical Immunology, Department of Medicine, University of Pittsburgh, Pittsburgh, Pennsylvania 15261, USA.

${ }^{6}$ The first two authors contributed equally to this work. 
recognition receptor, complement receptor 3 (CR3), triggers innate responses that consequently shape $\mathrm{T}_{\mathrm{H}} 1$ immunity. ${ }^{18}$ Interferon- $\gamma$ and granulocyte macrophage colony-stimulating factor activate macrophages to inhibit the growth of $H$. capsulatum. ${ }^{19}$ In contradistinction, type 2 cytokines polarize macrophages to an alternatively activated phenotype, thus providing a favorable environment for $H$. capsulatum to proliferate, and ultimately increase vulnerability to the disease. . $^{5,21}$

We have reported that enhanced susceptibility of CCR2 ${ }^{-1-}$ mice to $H$. capsulatum infection is primarily attributed to an exaggerated IL-4 response generated early in lungs. ${ }^{5}$ Here, we show that eosinophils were the instigators of the heightened IL4 response in infected mutant mice and depletion of these granulocytes improved fungal clearance. The pathologic role of eosinophils in subverting antifungal immunity was further evidenced in animals overexpressing these granulocytes. Weakening of host defenses against $H$. capsulatum was due to phagocytosis of the fungal yeasts by eosinophils that prompted a robust non-protective IL- 4 response. Finally, this phenomenon was also found to be conserved in human eosinophils as they internalized $H$. capsulatum and mounted an amplified IL-4 response in comparison with uninfected cells.

\section{RESULTS}

\section{Identification of IL-4 ${ }^{+}$cells in $\mathrm{CCR}^{-I-}$ mice during fungal infection}

CCR $2^{-1-}$ mice manifest an augmented fungal burden and exaggerated IL- 4 in the lungs. ${ }^{5}$ To identify the source of IL- 4 in infected mutant animals, we generated $\mathrm{CCR}^{-/-}$. IL-4 reporter mice (designated as CCR $2^{-1-}$.4get mice) by crossing $\mathrm{CCR} 2^{-1-}$ and 4get mice on a C57BL/6 background. Analogous to $\mathrm{CCR} 2^{-1-}$ mice, the transgenic reporter mice exhibited a heightened pulmonary fungal burden in comparison with the controls at day 7 of $H$. capsulatum infection. The mean \pm s.e.m. $\log _{10}$ CFU in CCR2 ${ }^{-/-} .4$ get mice $(7.29 \pm 0.11)$ exceeded that of WT.4get mice $(6.13 \pm 0.15), n=6, P<0.01$. Previous observations indicated that CCR2 ${ }^{-1-}$ mice mount an elevated IL-4 response as early as day 3 of infection. ${ }^{5}$ Concordantly, we found that CCR2 ${ }^{-/-}$.4get animals expressed higher percentage and absolute number of $\mathrm{IL}_{-} 4^{+}$cells in the lungs in comparison with wild-type (WT) controls at day 3 post infection (p.i.) (Figure 1a). Gating on the $\mathrm{IL}_{-} 4^{+}$cell population revealed that the majority of those cells were

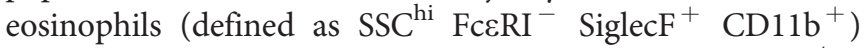
(Figure 1b). Elevated IL-4 $4^{+}$cells in the lungs of CCR2 ${ }^{-/-}$. 4get mice were not a result of a pre-existing bias toward an IL-4 response. Both the WT and CCR $2^{-1-}$ reporter mice expressed similar frequency of $\mathrm{IL}_{-} 4^{+}$cells before infection (Figure 1c). The finding of IL- 4 by transcripts is circumstantial evidence that protein is manufactured. To prove that eosinophils synthesized IL-4 protein, we performed intracellular staining. IL-4 was detected in the eosinophil population (Figure 1d).

To verify that CCR $2^{-1-}$ mice displayed increased accumulation of eosinophils during fungal infection, we analyzed these leukocytes in the lungs at day 3 p.i. Similar to the transgenic reporter mice, we observed a greater number and percentage of eosinophils (but not other cell populations) in CCR2 $2^{-1-}$ mice, in comparison with controls (Figure 1e,f). Together, these data suggested that eosinophils were the innate source of IL-4 in infected CCR $2^{-1-}$ animals.

\section{Eosinophil depletion in CCR2 ${ }^{-I-}$ mice results in decreased IL-4 and fungal burden}

To determine whether eosinophils were the chief contributors to the exaggerated IL- 4 response in $\mathrm{CCR} 2^{-/-}$mice, we depleted this cell population using the IL-5 neutralizing antibody. ${ }^{22}$ We observed specific diminution of the eosinophil population in the lungs using this monoclonal antibody (Figure 2a). Consequently, the $\alpha \mathrm{IL}-5$-treated $\mathrm{CCR} 2^{-/-}$. 4get animals expressed a reduced percentage and number of IL- $4^{+}$cells as opposed to control IgG-treated group after 3 days of infection (Figure $\mathbf{2 b}-\mathbf{d}$ ). An analogous decrement in frequency of these IL- $4^{+}$cells was also observed in animals injected with CCR3 antagonist, in comparison with DMSOtreated controls. The number of IL- $4^{+}$cells in the lungs of vehicle controls was $30.1 \pm 2.3 \times 10^{4}$ and $14.8 \times 10^{4}$ in those given the CCR3 antagonist $(P<0.05)$.

To substantiate that eosinophils were the causative agent of the dominant IL-4 response in CCR $2^{-/}$mice, the quantity of this cytokine was analyzed in the lungs of mice 7 days after they were challenged with $H$. capsulatum. A marked decrease in pulmonary IL-4 protein was noted following eosinophil depletion (Figure 2e). Furthermore, we detected diminished transcription of IL-4-regulated genes including Arg-1 and Chil3 in the lungs of $\alpha \mathrm{IL}-5$-treated group (Figure 2f,g). Finally, a significant lowering in fungal burden at week 1 of infection was observed in CCR2 ${ }^{-1-}$ mice that received IL-5 neutralizing antibody (Figure $2 \mathbf{h}$ ). Treatment of the WT mice with $\alpha$ IL-5 antibody did not diminish the pulmonary fungal burden (Figure 2h). These findings establish that eosinophils are the key instigators of the dominant IL-4 response in CCR2 ${ }^{-/-}$ mice that augments their susceptibility to $H$. capsulatum.

\section{IL-5 transgenic animals manifest enhanced susceptibility to $H$. capsulatum infection}

To test whether an increased number of eosinophils subvert host defense against $H$. capsulatum in an additional experimental model, we utilized the IL-5 transgenic mice. These animals exhibit \pm constitutive eosinophilia in their blood and peripheral organs including the lungs (Figure 3a). Although the transgenic mice are on a BALB/c background, we have previously reported similar $H$. capsulatum burden in C57BL/6 and $\mathrm{BALB} / \mathrm{c}$ strains. ${ }^{23}$ In comparison with WT controls, an elevated fungal burden was discerned in the IL-5 transgenic mice after 7 days of $H$. capsulatum challenge (Figure $3 \mathbf{b}$ ). Furthermore, the infected transgenic mice expressed higher amount of IL-4 in the lungs (Figure 3c). No noteworthy differences were observed in pulmonary IL- 4 concentration between the WT and IL-5 transgenic mice before infection. These data reinforce the deleterious role of eosinophils during histoplasmosis. 

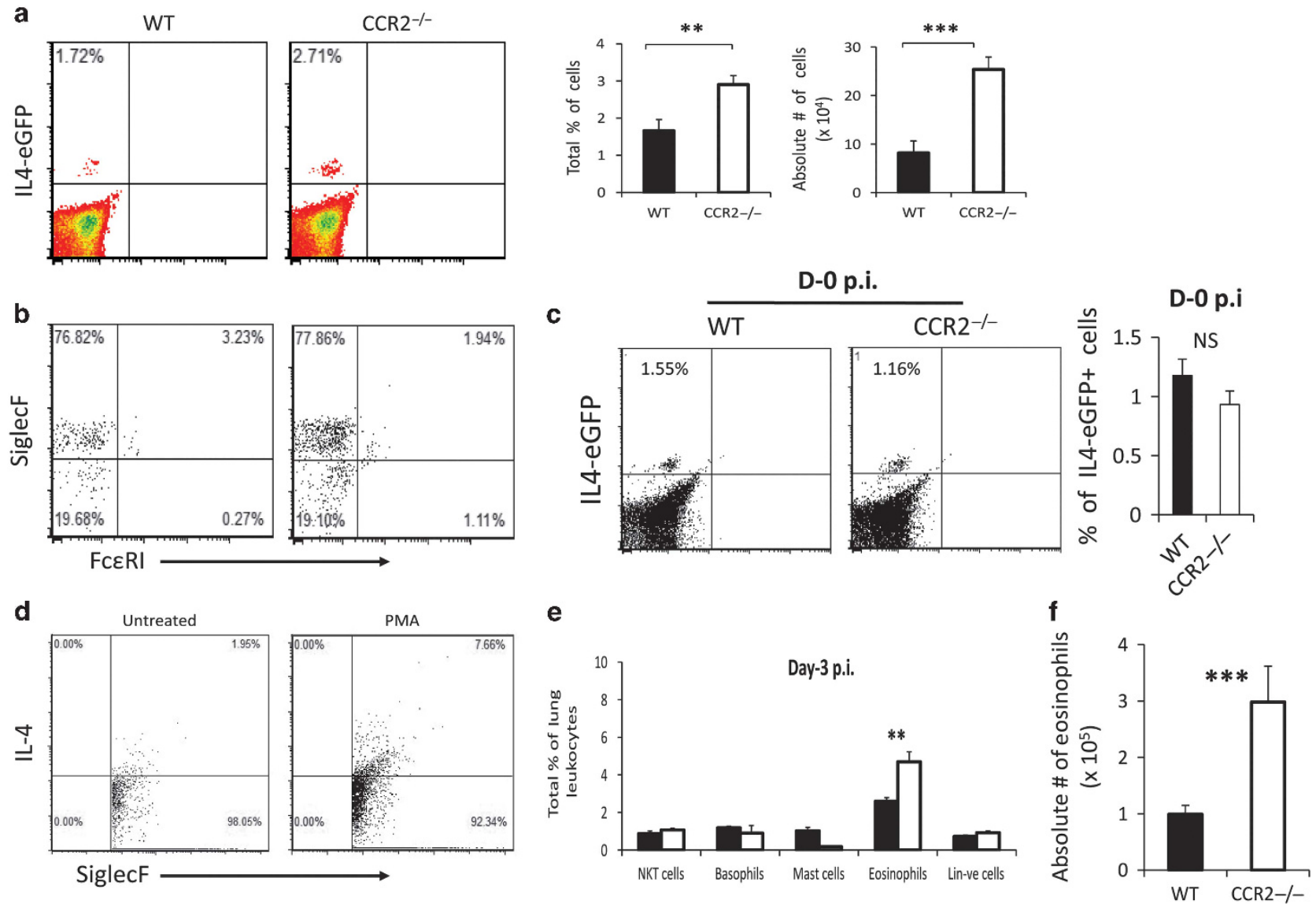

Figure 1 Identification of interleukin (IL)-4 ${ }^{+}$cells in $\mathrm{CCR}^{-1-}$ mice during $H$. capsulatum infection. (a) Quantitative analysis of IL4-eGFP ${ }^{+}$cells in the lungs of wild-type (WT) and CCR2 ${ }^{-1-}$ mice at day 3 post infection (p.i.) by flow cytometry. (b) Identification of IL4-eGFP ${ }^{+}$eosinophils at day 3 p.i. Eosinophils defined as SSC ${ }^{\text {hi }}$ SiglecF ${ }^{+} \mathrm{FcERI}^{-} \mathrm{CD}_{11 \mathrm{~b}^{+}}$. (c) Comparison of IL4-eGFP ${ }^{+}$cells in the lungs of WT and CCR2 ${ }^{-1-}$ mice before infection. (d) IL-4 expression in CCR2 ${ }^{-1-}$ lung eosinophils at day 3 p.i. Cells were stimulated for $4 \mathrm{~h}$ with $120 \mathrm{ng} \mathrm{ml}^{-1}$ phorbol 12 -myristate $13-a c e t a t e$ (PMA)/ ionomycin, the last $2 \mathrm{~h}$ in the presence of Brefeldin A (BFA). (e and $\mathbf{f})$ Analysis of leukocytes associated with innate IL-4 production in WT and CCR2 ${ }^{-1}$ (non-reporter) mice at day 3 p.i. All flow cytometry plots are representative of one of eight mice from two independent experiments. Graphical data are depicted as mean \pm s.e.m., $n=8$ from 2 independent experiments. ${ }^{* \star} P<0.01,{ }^{* \star *} P<0.005$.

\section{Phagocytosis of $H$. capsulatum by murine eosinophils results in IL-4 secretion}

A prior report has indicated that eosinophils display phagocytic activity against the pathogenic fungus Cryptococcus neoformans. ${ }^{24}$ To test whether these granulocytes phagocytose $H$. capsulatum yeasts, we infected murine bone marrow-derived eosinophils with GFP-labeled H. capsulatum. Flow-cytometric analysis revealed distinct association of yeasts with eosinophils at 1 and 5 multiplicity of infection (Figure 4a,b). To investigate whether $H$. capsulatum yeasts localized within the eosinophils, we employed confocal microscopy. Examination of Z-stacked images of infected cells demonstrated that they had completely internalized $\mathrm{GFP}^{+}$H. capsulatum (Figure 5). In five independent experiments, extended exposure $(24 \mathrm{~h})$ to $H$. capsulatum induced cell death in $85 \pm 4 \%$ of the eosinophils whereas death of unexposed eosinophils after $24 \mathrm{~h}$ was $45 \pm 3 \%(P<0.05)$.

Our in vivo findings suggested that eosinophils were a prominent source of IL-4 in fungal infection. We therefore measured the concentration of this cytokine in culture supernatants of $H$. capsulatum-infected eosinophils. We noted robust expression of IL-4 protein that increased with the duration and magnitude of infection (Figure 4c,d). These findings signify the phagocytic capacity of eosinophils against H. capsulatum and also that they are a potent source of IL-4 in fungal infection.

\section{H. capsulatum uptake by eosinophils is dependent on CR3} The CR3 complex (CD11b/CD18) promotes ingestion of nonopsonized $H$. capsulatum yeasts by phagocytes including macrophages and neutrophils. ${ }^{18,25}$ To test whether engagement of the same pattern recognition receptor was requisite for fungal uptake by eosinophils, we blocked the CD18 subunit on the cells. Eosinophils pre-treated with $\alpha \mathrm{CD} 18$ antibody displayed a marked decrease in phagocytosis of non-opsonized yeasts as compared with control IgG-treated cells (Figure 6a). The former group manifested a diminished IL-4 response following infection (Figure 6b). In these experiments, we used a monoclonal antibody directed against CD18 (clone GAME46). Others have reported that this antibody displays similar efficacy in blocking phagocytosis of $H$. capsulatum as the 

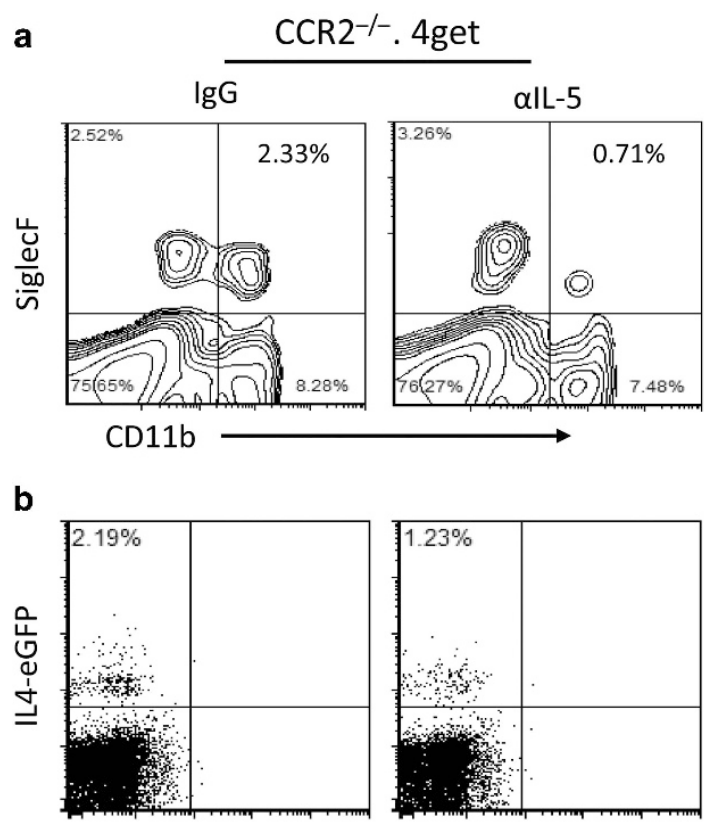

f

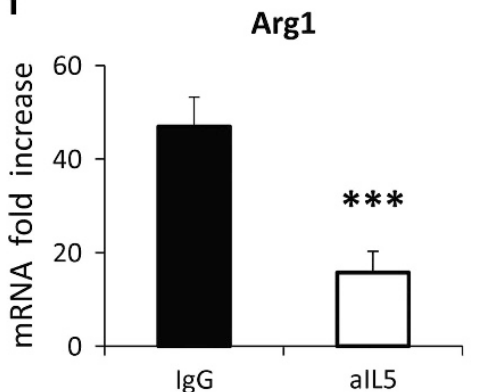

c

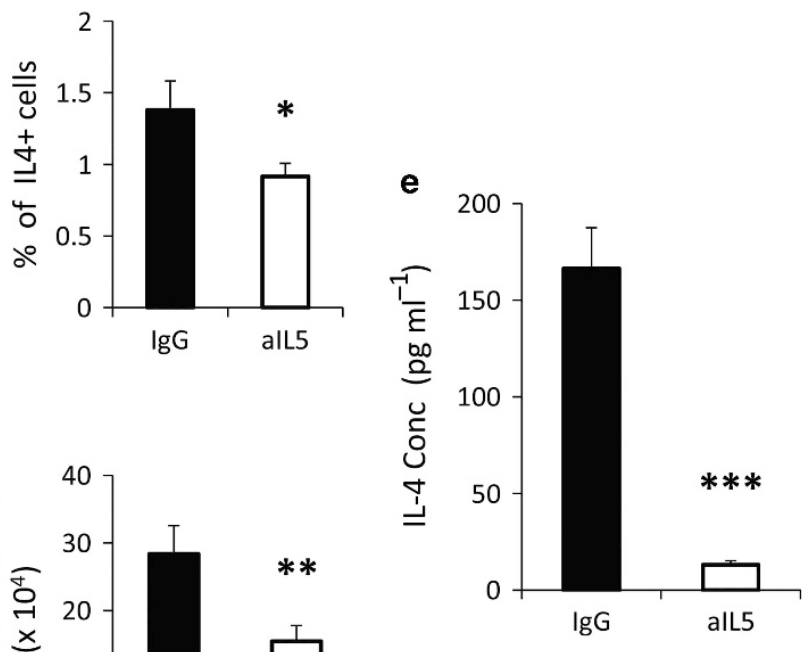

g

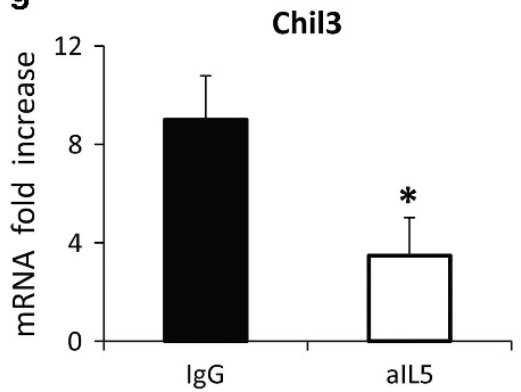

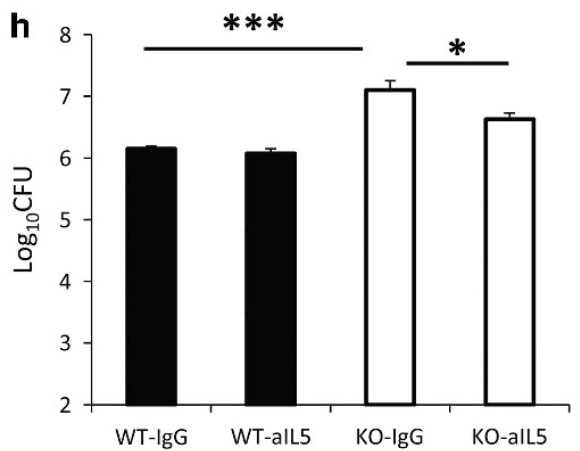

Figure 2 Consequence of eosinophil depletion in CCR2 ${ }^{-1-}$ mice. (a) Flow cytometric analysis of eosinophils in the lungs of CCR2 ${ }^{-1-} .4 \mathrm{get}$ mice treated with anti-IL5 or isotype control antibody at day 3 post infection (p.i.). (b-d) Flow cytometric analysis of pulmonary IL4-eGFP ${ }^{+}$cells in control IgG or anti-IL5-treated CCR2 ${ }^{-1-}$. 4 get mice at day 7 p.i. (e) Measurement of IL-4 protein concentration in lung homogenates of control IgG or anti-IL5-treated $\mathrm{CCR}^{-1-}$ mice at day 7 p.i by enzyme-linked immunosorbent assay (ELISA). ( $\mathbf{f}$ and $\mathbf{g}$ ) Quantitative real-time reverse transcription PCR (qRT-PCR) analysis of IL-4-dependent genes following eosinophil depletion (day 7 p.i). (h) Pulmonary fungal burden represented as $\log _{10} \mathrm{CFU}$ in control IgG or antiIL5-treated CCR2 ${ }^{-1-}$ mice at day 7 p.i. All flow cytometric plots are representative of 1 of $7-8$ mice from 2 independent experiments. Graphical data are depicted as mean \pm s.e.m., $n=7-8$ from 2 independent experiments. IL, interleukin. ${ }^{\star} P<0.05,{ }^{* \star} P<0.01,{ }^{* \star} P<0.005$.

anti-CR3 antibody, ${ }^{18}$ suggesting that the two can be used interchangeably. Inhibition of signaling through Syk kinase (downstream of CR3) has been shown to disrupt phagocytosis. ${ }^{18}$ To substantiate the contribution of CR3 in eosinophilic phagocytosis of fungal yeasts, we treated cells with piceatannol and exposed them to H. capsulatum. We detected a pronounced decrement in phagocytosis and IL-4 release by eosinophils (Figure 6c,d). As piceatannol blocks several signaling pathways, we examined the more specific Syk inhibitor Bay 61-3606. It sharply reduced binding as did the inhibition of JNK and PI3K (Figure 6c,d). Blockade by piceatannol reduced IL-4 release by eosinophils (Figure $6 \mathbf{6}$ ).

Uptake of $\boldsymbol{H}$. capsulatum by murine eosinophils in vivo We investigated whether murine eosinophils phagocytosed $H$. capsulatum in vivo. We utilized the CCR2 ${ }^{-1-}$ model since these animals mount an eosinophilic response in the lungs upon fungal challenge (as indicated above). We infected the mutant mice with GFP-labeled $H$. capsulatum and analyzed the leukocyte population 3 days later. The mice were infected with a high infectious dose $\left(2 \times 10^{7}\right.$ yeasts $)$ to increase the probability of detecting $H$. capsulatum-associated eosinophils. We observed a small fraction of $\mathrm{GFP}^{+}$eosinophils (SSChi $\mathrm{FcERI}^{-}$SiglecF $^{+}$ $\mathrm{CD}_{11} \mathrm{~b}^{+}$) in the lungs of CCR2 ${ }^{-l-}$ mice (Figure 7a). To confirm that eosinophils ingested yeast cells, we performed imaging flow cytometry using the stains for eosinophils mentioned above. We observed intracellular yeasts within eosinophils (Figure 7b). Thus, phagocytosis of $H$. capsulatum by eosinophils is not restricted to in vitro conditions but occurred in vivo.

\section{H. capsulatum infection induces an IL-4 response in human eosinophils}

We examined whether human eosinophils manifest similar properties as their murine counterparts. Eosinophils were 
a

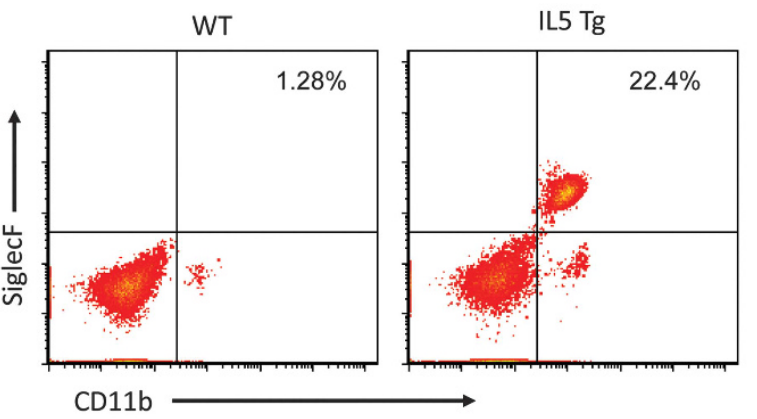

b

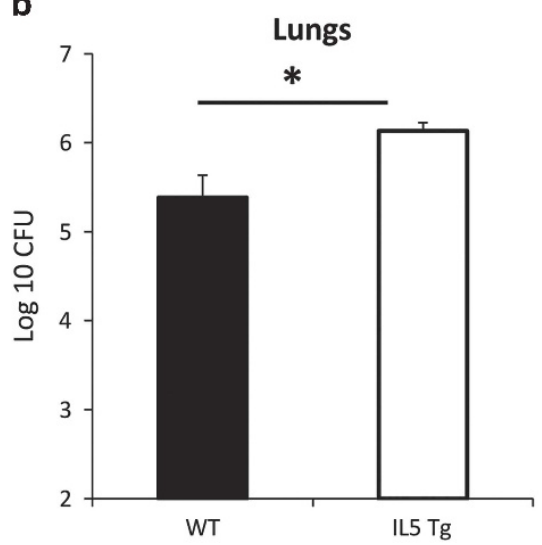

C

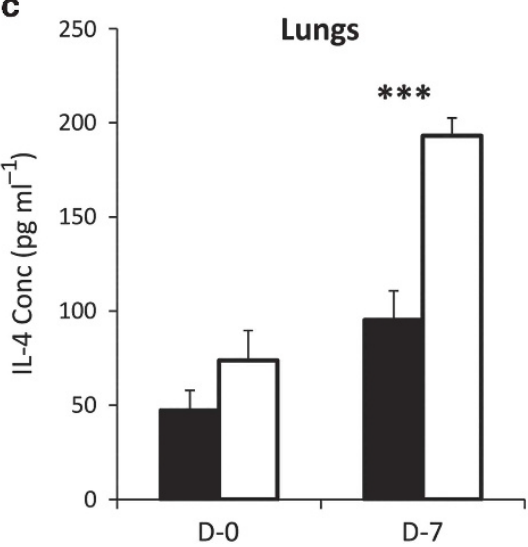

Figure 3 H. capsulatum infection in interleukin (IL)-5 transgenic mice. (a) Eosinophil influx in lungs of wild-type (WT) and IL5-transgenic mice before infection, as analyzed by flow cytometry. Flow cytometric plots representative of one of six mice from two independent experiments. Fungal burden depicted in $\log _{10}$ CFU (b), and IL-4 protein concentration (c) in lungs of WT and IL-5 transgenic animals after 7 days of $H$. capsulatum challenge. Values are represented as mean \pm s.e.m., $n=7-8$ from 2 independent experiments. ${ }^{*} P<0.05,{ }^{\star * *} P<0.005$.

purified from human peripheral blood and infected with $\mathrm{GFP}^{+}$ $H$. capsulatum for $4 \mathrm{~h}$. Flow-cytometric analysis indicated a clear association between these granulocytes and the yeasts (Figure 8a). These results were confirmed by imaging flow cytometry of infected cells (Figure $\mathbf{8 b}$ ). To determine whether H. capsulatum infection promulgated an IL-4 response in eosinophils, we measured the cytokine in cell-culture supernatants. No detectable IL-4 could be discerned (IL-4 $<12 \mathrm{pg} \mathrm{ml}^{-1}$ ). However, we observed amplification in IL-4 protein by intracellular staining of infected eosinophils as opposed to uninfected cells (Figure 8c). Thus, these data demonstrate that human eosinophils manifest heightened IL-4 response following phagocytosis of $H$. capsulatum.

\section{DISCUSSION}

CCR2 $2^{-1-}$ mice exhibit dampened immunity to H. capsulatum due to exaggerated IL-4 in the lungs. This dominant IL-4 response is detected at day 3 of fungal infection, raising the possibility that an innate cellular source is generating IL-4. We found eosinophils to be the primary initiators of non-protective IL-4 as depletion of this granulocyte population abrogated the IL- 4 response and improved the outcome of infection in CCR2 ${ }^{-1-}$ animals. The adverse impact of eosinophilia on histoplasmosis was also demonstrated in IL-5 transgenic animals that constitutively express high numbers of eosinophils. These mice manifested elevated pulmonary fungal burden that was accompanied by increased IL-4 protein concentrations. Mechanistic examination of IL-4 induction revealed that phagocytosis of $H$. capsulatum yeasts prompted the heightened cytokine response in murine and human eosinophils. Our findings reveal an unappreciated attribute of eosinophil biology that could potentially be detrimental to the host in intracellular fungal infections.

Overproduction of IL- 4 enhances susceptibility to intracellular microbial pathogens by disturbing the $\mathrm{T}_{\mathrm{H}} 1 / \mathrm{T}_{\mathrm{H}} 2$ balance in the host. ${ }^{4,26}$ Among fungi, IL-4 produced largely by $\mathrm{T}_{\mathrm{H}} 2$ is detrimental to host resistance or exaggerates immunemediated pathology. This scenario is evident in mice exposed to H. capsulatum, Cryptococcus neoformans, Candida albicans, or Aspergillus fumigatus. ${ }^{5,27,28}$ In experimental histoplasmosis, cryptococcosis, and candidiasis, enhanced production of type 2 cytokines leads to elevated fungal burdens. Likewise, in invasive aspergillosis, eosinophils enhances tissue pathology in invasive aspergillosis, ${ }^{28}$ and IL-4 exaggerates aspergillosis. ${ }^{29}$

We sought to determine the nature of the cells instigating IL-4 in CCR $2^{-1-}$ mice exposed to H. capsulatum. We chose to focus on day 3 of fungal infection since our previous data indicate that the dominant IL-4 response is initiated at this particular time point. Several innate cell populations including basophils, mast cells, NKT cells, and type II innate lymphoid cells have been shown to prompt IL-4 generation; however, we observed comparable percentages and numbers of these 

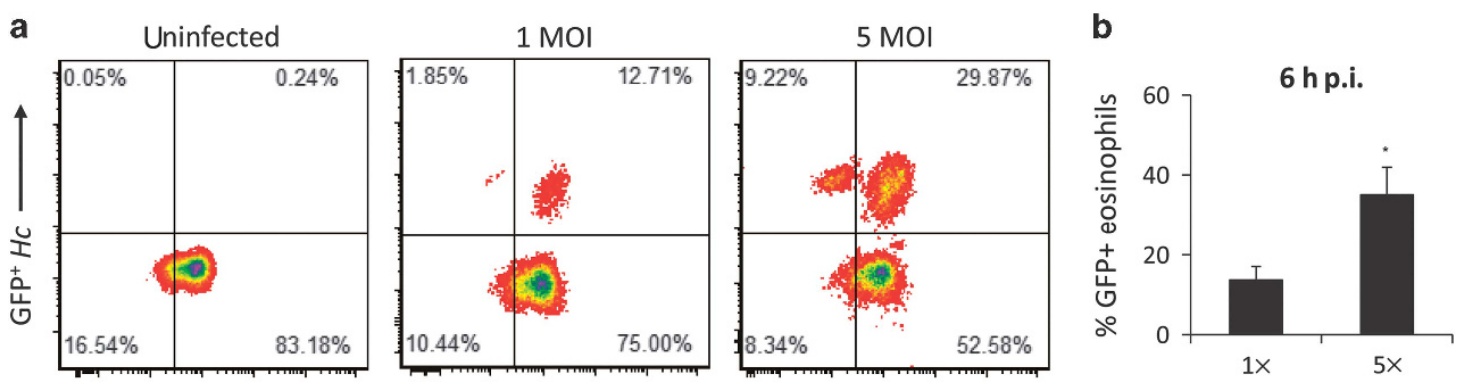

SiglecF

C

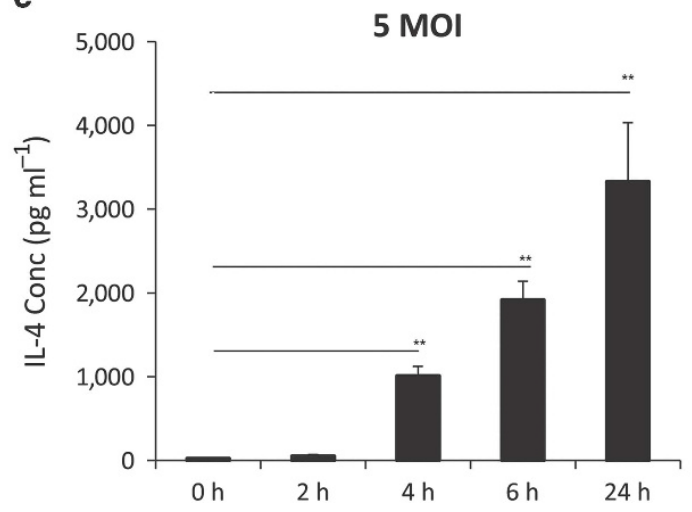

d

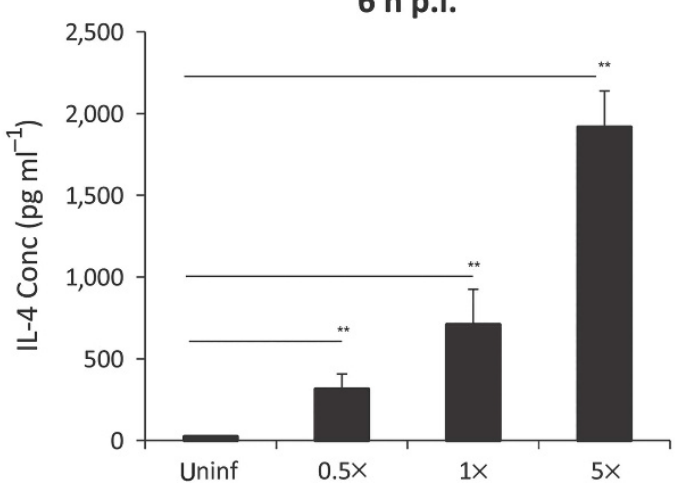

Figure 4 Phagocytosis of H. capsulatum by eosinophils results in interleukin (IL)-4 secretion. (a and b) Flow cytometric analysis of bone marrow-derived eosinophils challenged with 1 or 5 multiplicity of infection (MOI) GFP ${ }^{+} H$. capsulatum yeasts for $6 \mathrm{~h}$. Plots representative of one of five independent experiments. (c and d) Measurement of IL-4 protein concentration in culture supernatants of eosinophils infected with different MOI of $H$. capsulatum yeasts for varying time points as indicated. Values are mean \pm s.e.m. from at least four independent experiments. ${ }^{*} P<0.05,{ }^{* *} P<0.01$ as compared with control, either time 0 for $\mathbf{c}$ or uninfected for $\mathbf{d}$.

leukocytes in infected WT controls and CCR2 $2^{-1-}$ animals. Thus, it was unlikely that these cells made a significant contribution to the amplified IL-4 response in infected mutant mice. In contrast, we observed an increased pulmonary eosinophilic response in CCR2 ${ }^{-1-}$ mice that suggested a possible involvement of these granulocytes in triggering the elevated IL-4 in H. capsulatum infection. Indeed, depletion of eosinophils greatly diminished IL- 4 in infected CCR2 ${ }^{-1-}$ mice. $\mathrm{T}_{\mathrm{H}} 2$ cells did not contribute to this heightened IL-4 response since we have demonstrated earlier that loss of $\mathrm{CD} 4^{+}$ $\mathrm{T}$ cells does not impact pulmonary IL- 4 concentrations in CCR2 ${ }^{-1-}$ mice. ${ }^{5}$ This finding highlights a role for eosinophils in instigating type II immunity by releasing innate IL-4, a topic that has thus far remained highly contentious.

The inability to signal through CCR2 is largely associated with a failure to mobilize monocytes from the bone marrow and to diminish the number of monocyte-derived dendritic cells in response to exogenous stimuli. ${ }^{30}$ Our report highlights that in the absence of monocyte recruitment or conversion of these cells to monocyte-derived dendritic cells, there may be preference for attracting eosinophils. In our model, attraction of eosinophils to lungs depends on infection and is driven by CCR3. These results reveal an early influence of monocytes and/or monocyte-derived dendritic cells on tempering the quantity of chemokines that attract eosinophils. Our findings have been corroborated by a study demonstrating that CCR2 ${ }^{-1-}$ mice exhibit excessive numbers of eosinophils in adipose tissue as compared with WT, and these cells maintain a type 2 immune response in the fat. ${ }^{31}$ However, in our study, the elevation in eosinophils in the lungs required a provocation, i.e., fungal infection, and was not found in uninfected state.

Defective regulation of IL-4 responses during histoplasmosis augments vulnerability to the disease. ${ }^{32}$ This cytokine induces alternative activation of macrophages that is associated with uncontrolled $H$. capsulatum growth. Mechanistically, IL-4 drives the expression of arginase-1, an enzyme that diminishes the amount nitric oxide required for fungicidal activity in macrophages. ${ }^{33}$ In addition, alternatively activated macrophages exhibit augmented intracellular stores of zinc required for $H$. capsulatum proliferation. ${ }^{34}$ We observed increased expression of markers associated with alternative macrophage activation in addition to elevated fungal burden in infected CCR2 $2^{-1-}$ mice, thus indicating detrimental effects of eosinophil-derived IL-4 on the host. In another experimental model of IL-5 transgenic mice, higher numbers of eosinophils were found to subvert antifungal immunity against $H$. capsulatum. Heightened fungal burden was accompanied by amplified IL-4 concentrations in the lungs of these transgenic animals in comparison with infected controls, further emphasizing the adverse impact of IL-4 producing eosinophils on $H$. capsulatum infection. 


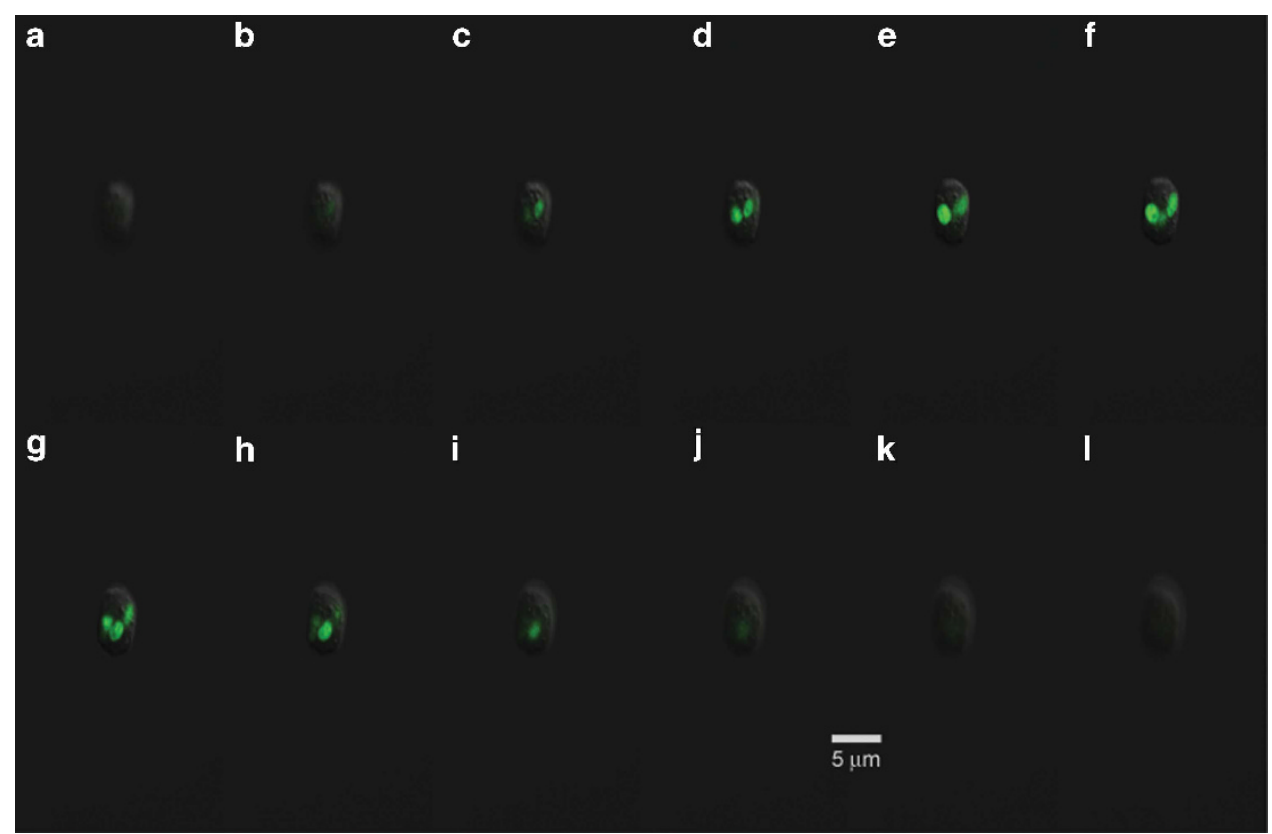

Figure 5 Phagocytosis of $H$. capsulatum yeasts by murine eosinophils. Z-stacked images of an eosinophil infected with 5 multiplicity of infection (MOI) of $H$. capsulatum. The images were collected at $0.66 \mu \mathrm{m}$ intervals $(1,000 \times$ magnification). Panels $b$ through $\mathrm{k}$ show yeast cells within an eosinophil. In panels a and I, yeast cells are not visible. Representative image of one of three independent experiments. $5 \mu \mathrm{m}$ bar is shown.

Another unexpected finding was that murine eosinophils phagocytosed fungal yeasts upon contact in in vitro and in vivo settings. Besides releasing IL-4, these cells were inefficient at fungal killing since we observed comparable $H$. capsulatum growth between eosinophil culture and control media (data not shown). In fact, prolonged exposure to $H$. capsulatum induced cell death in a majority of the eosinophils. The death of these cells may be one mechanism by which IL-4 is released. Although eosinophils manifest antimicrobicidal activity of eosinophils against C. neoformans, Staphylococcus aureus, and Escherichia coli, ${ }^{35,36}$ the net effect of these cells is likely to be negative given their ability to release IL-4.

CR3 is the major innate receptor that participates in detection and uptake of non-opsonized $H$. capsulatum by phagocytes. ${ }^{18}$ Eosinophils were found to engage the same receptor in phagocytosis of fungal yeasts. Inhibiting internalization of fungi also disrupted the ensuing IL-4 response in infected eosinophils. These observations are in agreement with a recent report describing the involvement of CR3 signaling in phagocytosis and downstream cytokine responses in H. capsulatum-infected macrophages. ${ }^{18}$ Although phagocytosis and activation of CR3 signaling are two independent biological events, they cannot be uncoupled in $H$. capsulatum infection. ${ }^{37}$ This is because blockade of one disrupts the other and vice versa. Hence, we were unable to determine whether activation of CR3 pathway without switching on the phagocytic machinery of eosinophils would prompt a strong IL-4 response.

In concordance with our findings in murine eosinophils, human eosinophils phagocytosed $H$. capsulatum yeasts and mounted an amplified IL-4 response. We failed to detect IL-4 protein in cell culture supernatants, rather, augmented intracellular protein content of the cytokine in infected cells was noted by flow cytometry. Others have reported that human eosinophils are not adept at secreting IL-4 in in vitro culture conditions despite possessing intracellular stores of the cytokine. ${ }^{38,39}$ Failure to detect IL-4 in H. capsulatum-infected human eosinophil cultures could likely be due to the limitations of an in vitro system.

Prior data suggest that a subset of patients with disseminated histoplasmosis may manifest a type II immune response phenotype. ${ }^{40}$ On the basis of our findings, it is possible that eosinophils are the origin of type II cytokines in that subgroup. Several case reports document the presence of eosinophilia in patients with disseminated histoplasmosis. ${ }^{41-45}$ These patients exhibited $>4 \%$ eosinophils coincident with the diagnosis of histoplasmosis. Moreover, eosinophilia has also been described in other $H$. capsulatum-infected mammals including canines. ${ }^{46}$ Apart from histoplasmosis, high numbers of eosinophils have been observed in individuals suffering from other fungal diseases such as coccidioidomycosis and paracoccidioidomycosis. ${ }^{47,48}$ In such reports, it is difficult to discern whether the eosinophilia was present before the onset of clinical symptomatology or was manifest only at the time of presentation. Regardless, the heightened number of eosinophils in these subjects may provide a clue that the balance between type I and type II immunity is perturbed.

In summary, we present compelling evidence that highlights the detrimental attribute of eosinophils in impairing host resistance to an intracellular fungal pathogen by instigating type II immunity. Although this cell population is critical for anti-helminth immunity, it enhances susceptibility to $H$. capsulatum by driving a non-protective IL-4 response. 
a

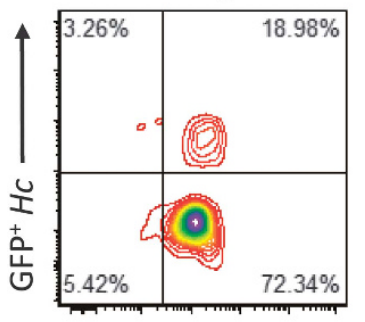

SiglecF

c

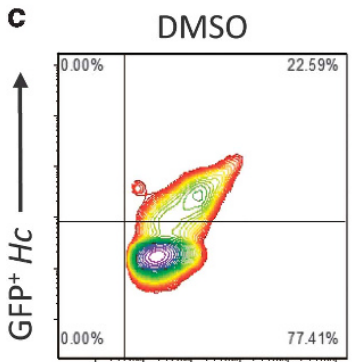

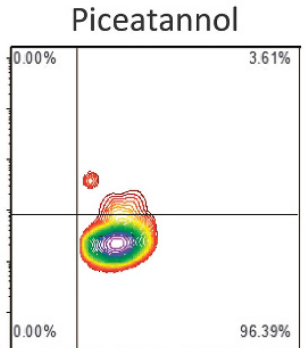

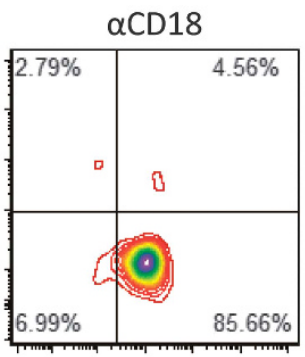

$66 \%$

$96.39 \%$

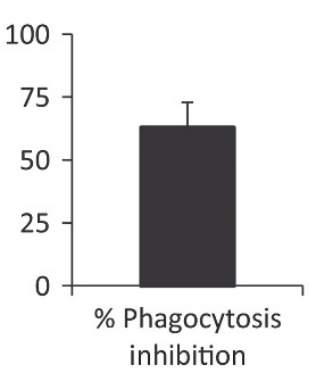

inhibition b

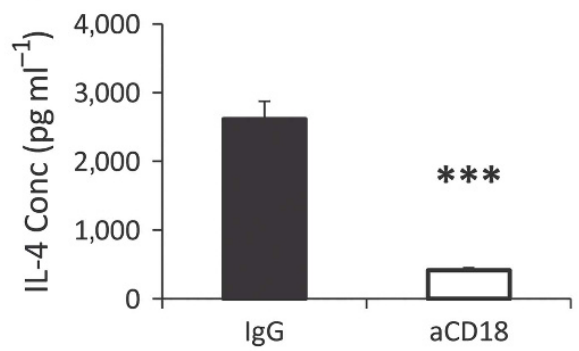

BAY 61-3606

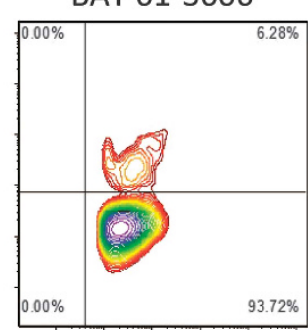

Ly294002

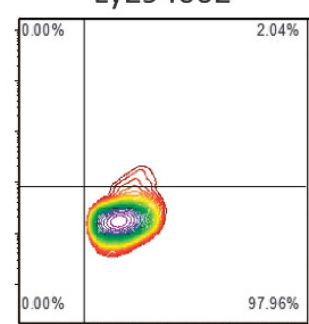

SP600125

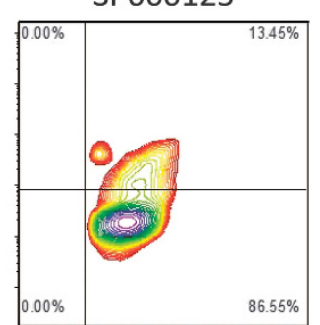

SiglecF

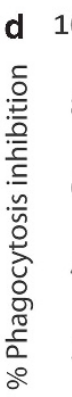

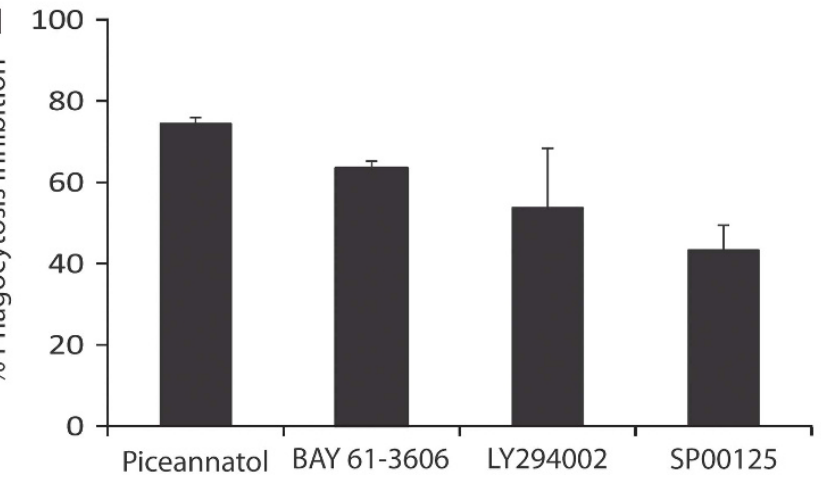

e

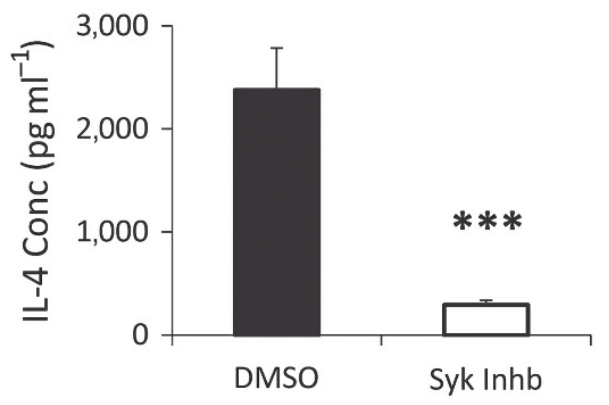

Figure 6 Eosinophil uptake of $H$. capsulatum is dependent on CR3. Flow cytometric analysis (a) and measurement of interleukin (IL)-4 protein in culture supernatants (b) of infected-bone marrow-derived eosinophils pre-incubated with control lgG or CD18 blocking antibody $\left(5 \mu \mathrm{g} \mathrm{ml}{ }^{-1}\right)$ for $90 \mathrm{~min}$ Subsequently, cells were infected with 5 multiplicity of infection (MOI) GFP ${ }^{+} H$. capsulatum yeasts for $6 \mathrm{~h}$. (c) Flow cytometric analysis of infected-bone

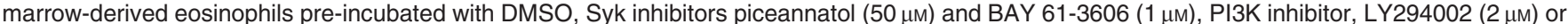
JNK inhibitor, SP600125 $\left(10 \mu \mathrm{g} \mathrm{ml}^{-1}\right)$ for $90 \mathrm{~min}$ before infection. Flow cytometry plots are representative of one of three independent experiments. (d) \% phagocytosis inhibition for each of the inhibitors. (e) Measurement of IL-4 protein in culture supernatants of infected-bone marrow-derived eosinophils pre-incubated with DMSO or piceannatol. Graphical values are represented as mean \pm s.e.m. from 4 to 5 independent experiments. ${ }^{* * *} P<0.005$.

Identification of the origins of IL-4 will aid in designing better therapeutic strategies to counter mycoses and also enhance our understanding of how type II immune responses are initiated and sustained. Specific depletion of these granulocytes in eosinophilic patients suffering from histoplasmosis or other mycotic infections may be a strategy that could potentially be used to improve the outcome of the diseases.

\section{METHODS}

Mice. Male C57BL/6 and breeding pairs of CCR2 ${ }^{-1-}(\mathrm{C} 57 \mathrm{BL} / 6$ background) mice were purchased from The Jackson Laboratory (Bar Harbor, ME). 4get mice (generously provided by Drs Fred Finkelman and Richard Locksley of Cincinnati Childrens' Hospital Medical Center and the University of California San Francisco, respectively) were backcrossed to C57BL/6 background ( $>10$ generations). CCR $2^{-1-} .4$ get mice were generated by crossing 4 get mice with
CCR ${ }^{-1-}$ animals. Male IL-5 transgenic mice (on BALB/c background) and sex-matched Balb/c WT controls were provided by Dr Marc Rothenberg. Animals were housed in isolator cages and were maintained by the Department of Laboratory Animal Medicine, which is accredited by the Association for Assessment and Accreditation of Laboratory Animal Care. All animal experiments were performed in accordance with the Animal Welfare Act guidelines of the National Institutes of Health and all protocols were approved by the Institutional Animal Care and Use Committee of the University of Cincinnati.

Preparation of $\boldsymbol{H}$. capsulatum and infection of mice. H. capsulatum yeast strain $\mathrm{G} 217 \mathrm{~B}$ and green fluorescent expressing yeast were grown for $72 \mathrm{~h}$ at $37^{\circ} \mathrm{C}$ as previously described. ${ }^{5}$ To produce infection in mice, 6- to 8-week-old animals were inoculated intranasally with $2 \times 10^{6}$ yeast cells in an $\sim 30 \mu$ l volume of HBSS (HyClone, Logan, UT).

Organ culture for $\boldsymbol{H}$. capsulatum. Organs were homogenized in sterile HBSS and serially diluted and plated onto Mycosel-agar plates 
a
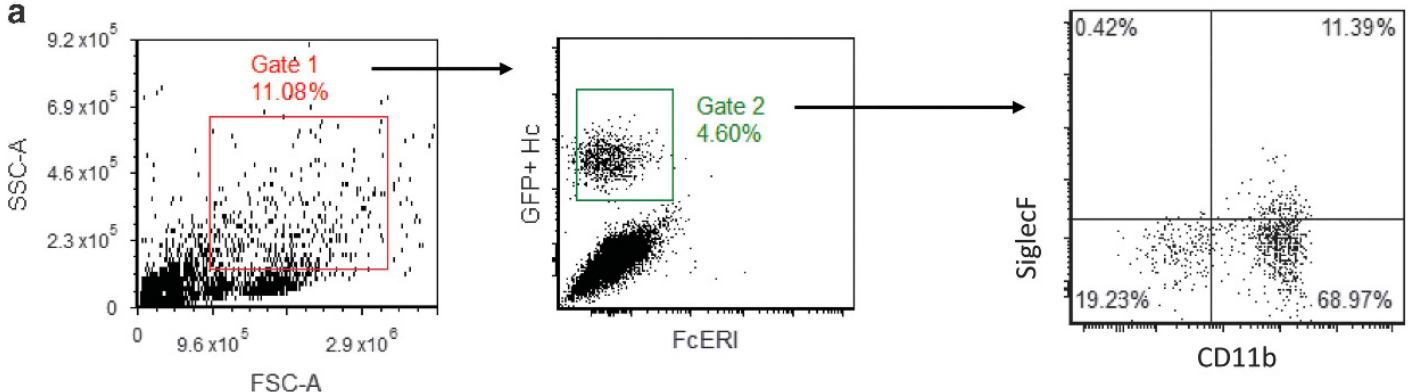

b

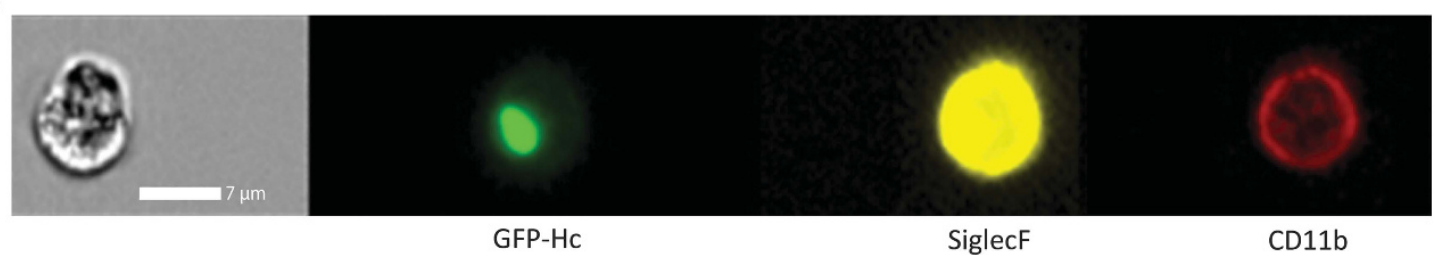

Figure 7 Association of $H$. capsulatum with eosinophils in vivo. (a) Flow cytometric analysis of $H$. capsulatum-infected eosinophils in vivo. CCR2 ${ }^{-1-}$ mice were infected with $1 \times 10^{7} \mathrm{GFP}^{+} \mathrm{H}$. capsulatum yeasts and $\mathrm{GFP}^{+}$eosinophils in the lungs were analyzed by flow cytometry 3 days post infection (p.i.). Plot representative of one of six mice from two independent experiments. (b) Microscopic analysis of GFP-Hc-infected eosinophils from lungs of $\mathrm{CCR}^{-1-}$ mice, 3 days after challenge and analyzed with an ImageStreamX flow cytometer.

containing 5\% sheep blood and 5\% glucose. Plates were incubated at $30^{\circ} \mathrm{C}$ for 8 days. The limit of detection was $10^{2} \mathrm{CFU}$.

In vivo depletion of eosinophils. In majority of the experiments, mice were injected intraperitoneally with $25 \mu \mathrm{g}$ of anti-human/mouse IL-5 monoclonal antibody (TRFK5 clone; R\&D Systems, Minneapolis, $\mathrm{MN}$ ) or isotype control antibody (purchased from Bio X Cell, Lebanon, $\mathrm{NH})$ on $-1,2$, and 5 days of infection. In some experiments, eosinophils were depleted by administering $1.5 \mathrm{mg}$ (in $\sim 50 \mu \mathrm{l} \mathrm{DMSO}$ ) CCR3 antagonist (SB 328437 from TOCRIS Bioscience, Bristol, UK) on days -1 and 2 p.i.

Isolation of lung leukocytes. Lungs were homogenized with the gentleMACS dissociator (Miltenyi Biotec, Auburn, CA) in $5 \mathrm{ml}$ of HBSS with $2 \mathrm{mg} \mathrm{ml}^{-1}$ of collagenase D (Roche, Mannheim, Germany) and $40 \mathrm{U} \mathrm{ml}^{-1}$ of DNase I (Roche) for $30 \mathrm{~min}$ at $37^{\circ} \mathrm{C}$. Following treatment, the homogenate was percolated through a $60-\mu \mathrm{m}$ nylon mesh (Spectrum Laboratories, Rancho Dominguez, CA) and washed three times with HBSS. Leukocytes were isolated by separation on Lympholyte M (Cedarlane Laboratories, Burlington, ON).

Flow cytometry and cell sorting. The phenotype of cells from mouse lungs was determined by incubating lung leukocytes with the indicated antibodies and CD16/32 to limit non-specific binding. Leukocytes were stained at $4{ }^{\circ} \mathrm{C}$ for $15 \mathrm{~min}$ in PBS containing $1 \%$ BSA and $0.01 \%$ sodium azide. Cells were stained with combinations of the following antibodies: PE-conjugated CD3, FceRI, and SiglecF; PerCP-conjugated cKit, and Streptavidin; Biotinylated-FceRI; and APC-conjugated NK1.1, CD49b, and CD11b from BD Biosciences (San Diego, CA). PE-conjugated Lineage cocktail was purchased from BioLegend (San Diego, CA). Human cells were stained with Alexa Fluor 647conjugated CD193 from BD Biosciences. For intracellular IL-4 staining, human eosinophils were incubated with Cytofix/ Cytoperm (BD Biosciences), washed in Permeabilization Buffer (BD Biosciences), and stained for $60 \mathrm{~min}$ with $\mathrm{PE}$-conjugated anti-human IL-4 (MyBioSource, San Diego, CA). Cells were washed and resuspended in $1 \%$ paraformaldehyde to fix. Appropriate isotype controls were performed in parallel. Data were acquired using a BD Accuri C6 (BD Biosciences) flow cytometer and analyzed using the FCS Express 4.0 Software (DeNovo Software, Glendale, CA). For cell sorting experiments, $\mathrm{SSC}^{\text {hi }}$ SiglecF ${ }^{+} \mathrm{FccRI}^{-} \mathrm{CD}^{-} 1 \mathrm{~b}^{+}$leukocytes from the lungs of CCR2 $2^{-1-}$ mice were isolated at day 3 p.i. using 5-laser FACS Aria II (BD Biosciences) in a BSL-2 facility. For imaging ingestion of fungi by eosinophils, we used an ImageStreamX flow cytometer (Amnis, Seattle, WA) and analyzed using the IDEAS Application 6.1 software, Amnis.

Generation of bone marrow-derived eosinophils. Bone marrow cells were isolated from the hind tibia and femurs of 6- to 10-week-old mice by flushing with HBSS, and erythrocytes were lysed using RBC lysis buffer. Following a density gradient of Histopaque 1083 (SigmaAldrich, St Louis, MO), the low-density bone marrow cells were collected and plated at $1 \times 10^{6}$ cells per $\mathrm{ml}$ in Iscove's Modified Dulbecco's Medium (Life Technologies, Grand Island, NY) supplemented with $10 \%$ fetal bovine serum, $0.1 \%$ gentamycin sulfate, $200 \mathrm{~mm}$ L-glutamine (Life Technologies), and $55 \mu \mathrm{M}$ 2-mercaptoethanol. During the first 4 days, the medium also contained stem cell factor (PeproTech, Rocky Hill, NJ) and Fms-like tyrosine kinase 3 ligand (PeproTech) at $100 \mathrm{ng} \mathrm{ml}^{-1}$ each. From day 4 to day 14 , the cells were cultured in medium containing $10 \mathrm{ng} \mathrm{ml}^{-1} \mathrm{IL}-5$ (PeproTech). The medium was changed every 2 days until day 14 . On the final day of the culture, differentiated eosinophils were collected, pooled, and plated for at least $1 \mathrm{~h}$ in a tissue culture dish to remove any contaminating cells such as stromal cells or macrophages. Finally, the non-adherent cells were collected, washed, counted, and incubated with different treatments, according to the experiments.

Isolation of human eosinophils from peripheral blood. Human blood was purchased from the Hoxworth Blood Center, Cincinnati, $\mathrm{OH}$; and eosinophils were isolated using EasySep Human Eosinophil Enrichment Kit (Stemcell Technologies, Vancouver, BC) as per the manufacturer's protocol. The cell purity was $>95 \%$ in all experiments (determined by flow cytometry and H\&E staining).

$\boldsymbol{H}$. capsulatum association with eosinophils. For in vitro murine eosinophil experiments, cells were cultured in IMDM in the presence of recombinant murine IL-5 $\left(10 \mathrm{ng} \mathrm{ml}^{-1}\right)$ before being exposed to $\mathrm{GFP}^{+} H$. capsulatum yeasts. Fungal association with eosinophils was quantified by flow cytometry. To inhibit $H$. capsulatum internalization, eosinophils were pretreated with anti-CD18 (clone GAME-46; BD Biosciences), Piceatannol (TOCRIS), BAY 61-3606 (EMD Millipore, Darmstadt, Germany), Ly294002 (Santa Cruz 


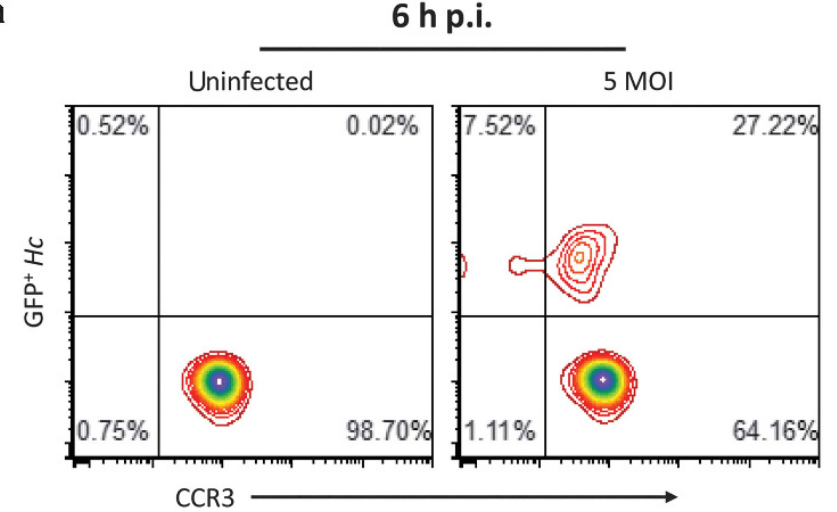

b

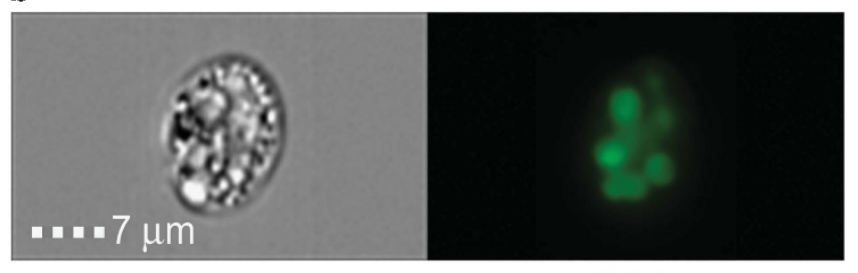

GFP-Hc

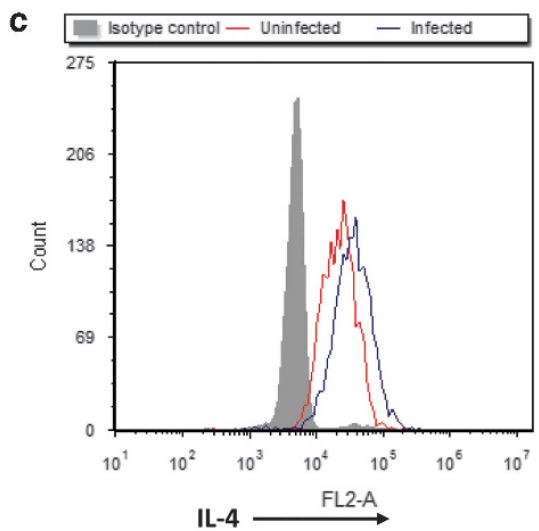

Figure 8 H. capsulatum infection and interleukin (IL)-4 response in human eosinophils. (a) Flow cytometric analysis of human eosinophils incubated without or with 5 multiplicity of infection (MOI) GFP ${ }^{+} \mathrm{H}$. capsulatum yeasts for $6 \mathrm{~h}$. (b) Infected human eosinophils analyzed with an ImageStreamX flow cytometer. (c) Flow cytometric analysis of IL-4 mean fluorescence intensity (MFI) in infected and uninfected human eosinophils. Plots and images are representative of one of three independent experiments.

Biotechnology, Santa Cruz, CA), or SP600125 (Santa Cruz) 90 min before infection. Human eosinophils were cultured in RPMI medium with recombinant human IL-5 $\left(10 \mathrm{ng} \mathrm{ml}^{-1}\right)$ and were subjected to infection with $\mathrm{GFP}^{+} H$. capsulatum.

Confocal microscopy. Eosinophils were infected with $\mathrm{GFP}^{+}$ H. capsulatum for $6 \mathrm{~h}$. Cells were then washed with PBS containing $1 \%$ BSA and mounted on glass slides using Fluromount-G (SouthernBiotech, Birmingham, AL). Images were acquired on a Zeiss LSM710 confocal microscope (Munich, Germany) and analyzed with the ImageJ software (in the public domain).

RNA isolation, cDNA synthesis, and quantitative real-time reverse transcription PCR. Total RNA from whole lungs of mice was isolated using TRIzol (Invitrogen, Carlsbad, CA). Oligo(dT)-primed cDNA was prepared by using the reverse transcriptase system (Promega, Madison, WI) according to the manufacturer's instructions.
Quantitative real-time PCR for analysis of gene transcription was performed using TaqMan master mixture and primers obtained from Applied Biosystems (Foster City, CA). Samples were analyzed with ABI Prism 7500 (Applied Biosystems). In each experiment, the hypoxanthine phosphoribosyl transferase housekeeping gene was used as an internal control. The conditions used for amplification were $50{ }^{\circ} \mathrm{C}$ for $2 \mathrm{~min}$ and $95^{\circ} \mathrm{C}$ for $10 \mathrm{~min}$, followed by 40 cycles of $95^{\circ} \mathrm{C}$ for $15 \mathrm{~s}$ and $60^{\circ} \mathrm{C}$ for $1 \mathrm{~min}$.

Measurement of IL-4 by enzyme-linked immunosorbent assay. IL-4 protein concentration was quantified in lung homogenates (dissolved in $5 \mathrm{ml} \mathrm{HBSS}$ ) and eosinophil-culture supernatants by using an enzyme-linked immunosorbent assay kit that was purchased from R\&D Systems.

Statistics. Statistics were performed using the Student's $t$-test or oneway ANOVA with Boneferroni's correction. $P$ value of $<0.05$ was considered as statistically significant. For all graphs, ${ }^{\star} P=0.01-0.05$, ${ }^{* *} P=0.005-0.01$, and ${ }^{* *} P<0.005$.

\section{ACKNOWLEDGMENTS}

We would like to thank J. Besse and M. Mingler for assistance with murine eosinophil experiments and Dr Newman for studies involving human eosinophils. We thank $\mathrm{Dr}$ Hogan for his valuable suggestions and J. Mohammed for sorting and flow-cytometry support. This work was supported by $\mathrm{NIH}$ grant Al-083313 (GSD), T32 HL-007752 (CB), and Al045898 (MER) from the National Institutes of Health.

\section{DISCLOSURE}

The authors declared no conflict of interest.

Official journal of the Society for Mucosal Immunology

\section{REFERENCES}

1. Finkelman, F.D. \& Urban, J.F. Jr. The other side of the coin: the protective role of the TH2 cytokines. J. Allergy Clin. Immunol. 107, 772-780 (2001).

2. Zhao, A. et al. Dependence of $\mathrm{IL}-4, \mathrm{IL}-13$, and nematode-induced alterations in murine small intestinal smooth muscle contractility on Stat6 and enteric nerves. J. Immunol. 171, 948-954 (2003).

3. Shea-Donohue, T. et al. The role of IL-4 in Heligmosomoides polygyrusinduced alterations in murine intestinal epithelial cell function. J. Immunol. 167, 2234-2239 (2001).

4. Kahnert, A. et al. Alternative activation deprives macrophages of a coordinated defense program to Mycobacterium tuberculosis. Eur. J. Immunol. 36, 631-647 (2006).

5. Szymczak, W.A. \& Deepe, G.S. Jr. The CCL7-CCL2-CCR2 axis regulates IL-4 production in lungs and fungal immunity. J. Immunol. 183, 1964-1974 (2009).

6. He, R., Oyoshi, M.K., Garibyan, L., Kumar, L., Ziegler, S.F. \& Geha, R.S. TSLP acts on infiltrating effector T cells to drive allergic skin inflammation. Proc. Natl. Acad. Sci. USA 105, 11875-11880 (2008).

7. Perkins, C., Wills-Karp, M. \& Finkelman, F.D. IL-4 induces IL-13independent allergic airway inflammation. J. Allergy Clin. Immunol. 118, 410-419 (2006).

8. Bouffi, C. et al. IL-33 markedly activates murine eosinophils by an NF-kappaB-dependent mechanism differentially dependent upon an IL-4driven autoinflammatory loop. J. Immunol. 191, 4317-4325 (2013).

9. Williams, C.M. \& Galli, S.J. The diverse potential effector and immunoregulatory roles of mast cells in allergic disease. J. Allergy Clin. Immunol. 105, 847-859 (2000).

10. Schroeder, J.T., Lichtenstein, L.M., Roche, E.M., Xiao, H. \& Liu, M.C. IL-4 production by human basophils found in the lung following segmental allergen challenge. J. Allergy Clin. Immunol. 107, 265-271 (2001).

11. Lee, Y.J., Holzapfel, K.L., Zhu, J., Jameson, S.C. \& Hogquist, K.A. Steadystate production of IL-4 modulates immunity in mouse strains and is determined by lineage diversity of iNKT cells. Nat. Immunol. 14, 1146-1154 (2013).

12. Doherty, T.A., Khorram, N., Lund, S., Mehta, A.K., Croft, M. \& Broide, D.H. Lung type 2 innate lymphoid cells express cysteinyl leukotriene receptor 1 , 
which regulates TH2 cytokine production. J. Allergy Clin. Immunol. 132, 205-213 (2013).

13. Mogbel, R. et al. Identification of messenger RNA for IL-4 in human eosinophils with granule localization and release of the translated product. J. Immunol. 155, 4939-4947 (1995).

14. Hogan, S.P. et al. Eosinophils: biological properties and role in health and disease. Clin. Exp. Allergy 38, 709-750 (2008).

15. Wu, D. et al. Eosinophils sustain adipose alternatively activated macrophages associated with glucose homeostasis. Science 332, 243-247 (2011).

16. Antinori, S. Histoplasma capsulatum: more widespread than previously thought. Am. J. Trop. Med. Hyg. 90, 982-983 (2014).

17. Brown, G.D., Denning, D.W., Gow, N.A., Levitz, S.M., Netea, M.G. \&White, T.C. Hidden killers: human fungal infections. Sci. Transl. Med. 4, 165rv113 (2012).

18. Lin, J.S., Huang, J.H., Hung, L.Y., Wu, S.Y. \& Wu-Hsieh, B.A. Distinct roles of complement receptor 3 , Dectin-1, and sialic acids in murine macrophage interaction with Histoplasma yeast. J. Leukoc. Biol. 88, 95-106 (2010).

19. Kroetz, D.N. \& Deepe, G.S. The role of cytokines and chemokines in Histoplasma capsulatum infection. Cytokine 58, 112-117 (2012).

20. Gildea, L.A., Gibbons, R., Finkelman, F.D. \& Deepe, G.S. Jr. Overexpression of interleukin- 4 in lungs of mice impairs elimination of Histoplasma capsulatum. Infect. Immun. 71, 3787-3793 (2003).

21. Verma, A., Kroetz, D.N., Tweedle, J.L. \& Deepe, G.S. Jr. Type ॥ cytokines impair host defense against an intracellular fungal pathogen by amplifying macrophage generation of IL-33. Mucosal Immunol. 8, 380389 (2015).

22. Van Oosterhout, A.J., Ladenius, A.R., Savelkoul, H.F., Van Ark, I., Delsman, K.C. \& Nijkamp, F.P. Effect of anti-IL-5 and IL-5 on airway hyperreactivity and eosinophils in guinea pigs. Am. Rev. Respir. Dis. 147, 548-552 (1993).

23. Deepe, G.S. Jr., Gibbons, R., Brunner, G.D. \& Gomez, F.J. A protective domain of heat-shock protein 60 from Histoplasma capsulatum. J. Infect. Dis. 174, 828-834 (1996).

24. Garro, A.P., Chiapello, L.S., Baronetti, J.L. \& Masih, D.T. Rat eosinophils stimulate the expansion of Cryptococcus neoformans-specific CD4(+) and CD8(+) T cells with a T-helper 1 profile. Immunology 132, 174-187 (2011).

25. Schnur, R.A. \& Newman, S.L. The respiratory burst response to Histoplasma capsulatum by human neutrophils. Evidence for intracellular trapping of superoxide anion. J. Immunol. 144, 4765-4772 (1990).

26. Sato, N. et al. CC chemokine receptor (CCR)2 is required for langerhans cell migration and localization of Thelper cell type 1 (Th1)-inducing dendritic cells. Absence of CCR2 shifts the Leishmania major-resistant phenotype to a susceptible state dominated by Th2 cytokines, B cell outgrowth, and sustained neutrophilic inflammation. J. Exp. Med. 192, 205-218 (2000).

27. Traynor, T.R., Kuziel, W.A., Toews, G.B. \& Huffnagle, G.B. CCR2 expression determines $\mathrm{T} 1$ versus $\mathrm{T} 2$ polarization during pulmonary Cryptococcus neoformans infection. J. Immunol. 164, 2021-2027 (2000).

28. O'Dea, E.M. et al. Eosinophils are recruited in response to chitin exposure and enhance Th2-mediated immune pathology in Aspergillus fumigatus infection. Infect. Immun. 82, 3199-3205 (2014).

29. Cenci, E. et al. Interleukin-4 causes susceptibility to invasive pulmonary aspergillosis through suppression of protective type I responses. J. Infect. Dis. 180, 1957-1968 (1999).

30. Serbina, N.V. \& Pamer, E.G. Monocyte emigration from bone marrow during bacterial infection requires signals mediated by chemokine receptor CCR2. Nat. Immunol. 7, 311-317 (2006).

31. Bolus, W.R., Gutierrez, D.A., Kennedy, A.J., Anderson-Baucum, E.K. \& Hasty, A.H. CCR2 deficiency leads to increased eosinophils, alternative macrophage activation, and type 2 cytokine expression in adipose tissue. J. Leukoc. Biol. 98, 467-477 (2015).
32. Deepe, G.S. Jr., Gibbons, R. \& Woodward, E. Neutralization of endogenous granulocyte-macrophage colony-stimulating factor subverts the protective immune response to Histoplasma capsulatum. J. Immunol. 163, 4985-4993 (1999).

33. Davis, M.J. et al. Macrophage M1/M2 polarization dynamically adapts to changes in cytokine microenvironments in Cryptococcus neoformans infection. MBio 4, e00264-213 (2013).

34. Winters, M.S., Chan, Q., Caruso, J.A. \& Deepe, G.S. Jr. Metallomic analysis of macrophages infected with Histoplasma capsulatum reveals a fundamental role for zinc in host defenses. J. Infect. Dis. 202, 1136-1145 (2010).

35. Garro, A.P., Chiapello, L.S., Baronetti, J.L. \& Masih, D.T. Eosinophils elicit proliferation of naive and fungal-specific cells in vivo so enhancing a $T$ helper type 1 cytokine profile in favour of a protective immune response against Cryptococcus neoformans infection. Immunology 134, 198-213 (2011).

36. Yazdanbakhsh, M., Eckmann, C.M., Bot, A.A. \& Roos, D. Bactericidal action of eosinophils from normal human blood. Infect. Immun. 53, 192-198 (1986).

37. Newman, S.L., Bucher, C., Rhodes, J. \& Bullock, W.E. Phagocytosis of Histoplasma capsulatum yeasts and microconidia by human cultured macrophages and alveolar macrophages. Cellular cytoskeleton requirement for attachment and ingestion. J. Clin. Invest. 85, 223-230 (1990).

38. Woerly, G. et al. Human eosinophils express and release IL-13 following CD28-dependent activation. J. Leukoc. Biol. 72, 769-779 (2002).

39. Woerly, G., Roger, N., Loiseau, S., Dombrowicz, D., Capron, A. \& Capron, M. Expression of CD28 and CD86 by human eosinophils and role in the secretion of type 1 cytokines (interleukin 2 and interferon gamma): inhibition by immunoglobulin a complexes. J. Exp. Med. 190, 487-495 (1999).

40. Cox, R.A. Immunologic studies of patients with histoplasmosis. Am. Rev. Respir. Dis. 120, 143-149 (1979).

41. Bullock, W.E., Artz, R.P., Bhathena, D. \& Tung, K.S. Histoplasmosis. Association with circulating immune complexes, eosinophilia, and mesangiopathic glomerulonephritis. Arch. Intern. Med. 139, 700-702 (1979).

42. Wheat, L.J., Slama, T.G. \& Zeckel, M.L. Histoplasmosis in the acquired immune deficiency syndrome. Am. J. Med. 78, 203-210 (1985).

43. Mackenjee, M.K. \& Coovadia, H.M. Histoplasmosis treated with a sulphonamide. A case report. S. Afr. Med. J. 50, 2015-2016 (1976).

44. Gantz, N.M. \& Harris, N.L. Case 24-1984. N. Engl. J. Med. 310, 1584-1594 (1984).

45. Reddy, P., Gorelick, D.F., Brasher, C.A. \& Larsh, H. Progressive disseminated histoplasmosis as seen in adults. Am. J. Med. 48, 629-636 (1970).

46. Clinkenbeard, K.D., Cowell, R.L. \& Tyler, R.D. Disseminated histoplasmosis in dogs: 12 cases (1981-1986). J. Am. Vet. Med. Assoc. 193, 1443-1447 (1988).

47. Martinez, R. \& Moya, M.J. Primary complex of paracoccidioidomycosis and hypereosinophilia. J. Bras. Pneumol. 35, 1259-1262 (2009).

48. Schermoly, M.J. \& Hinthorn, D.R. Eosinophilia in coccidioidomycosis. Arch. Intern. Med. 148, 895-896 (1988).

(c)(1) $\odot \odot$ This work is licensed under a Creative Commons Attribution-NonCommercial-NoDerivs 4.0 International License. The images or other third party material in this article are included in the article's Creative Commons license, unless indicated otherwise in the credit line; if the material is not included under the Creative Commons license, users will need to obtain permission from the license holder to reproduce the material. To view a copy of this license, visit http://creativecommons.org/licenses/by-nc-nd/4.0/ 